See Article page XXX.

\section{Commentary: Making sense of minor changes: Type B aortic dissection in a new light!}

\author{
Christoph A. Nienaber, MD, PhD, ${ }^{a, b}$ \\ Ibrahim Akin, $\mathrm{MD}, \mathrm{PhD},{ }^{\mathrm{c}}$ and \\ Xun Yuan, MBBS, MMED ${ }^{\mathrm{a}, \mathrm{b}}$
}

The clinical research group around Miyoshi and colleagues ${ }^{1}$ from Kobe City Hospital in Japan have provided an important piece in the puzzle of identifying patients with uncomplicated aortic dissection and an untoward clinical outcome. Aortic enlargement within 2 weeks of acute type B aortic dissection or intramural hematoma of greater between 2 and $5 \mathrm{~mm}$ portends powerful prognostic information.

First, a risk estimate of 3.63 with early moderate enlargement is a robust marker (even with $24 \%$ of patients lost to follow-up) and a clear harbinger of adverse events. Second, this important new signal should prompt early imaging follow-up at 2 weeks in every patient with aortic dissection as a new standard of care to increase the yield of patients with dooming complications. Third, the observational finding of early enlargement may in fact serve as a novel trigger to recommend early endoluminal scaffolding with the goal to realign dissected aorta regardless of symptoms and induce the process of remodeling to stabilize the aorta. Although the gathering of data was retrospective, the signal emerging from this cohort is convincing while it still awaits prospective validation. Nevertheless, the authors confirm conclusions from previous underpowered prospective trials that clearly indicated the benefit of timely endoluminal

\footnotetext{
From the ${ }^{\mathrm{a}}$ Cardiology and Aortic Centre, Royal Brompton and Harefield Hospitals, Guy's and St Thomas' NHS Foundation Trust, London, United Kingdom; 'Department of Cardiology, National Heart and Lung Institute, Faculty of Medicine, Imperial College London, London, United Kingdom; and ${ }^{\mathrm{c} C}$ ardiology Department, Medical Faculty Mannheim, University of Heidelberg, Heidelberg, Germany. Disclosures: The authors reported no conflicts of interest.

The Journal policy requires editors and reviewers to disclose conflicts of interest and to decline handling or reviewing manuscripts for which they may have a conflict of interest. The editors and reviewers of this article have no conflicts of interest.

Received for publication Sept 28, 2021; revisions received Sept 28, 2021; accepted for publication Sept 28, 2021.

Address for reprints: Christoph A. Nienaber, MD, PhD, Royal Brompton and Harefield Hospital NHS Foundation Trust, Imperial College, London (E-mail: c.nienaber@rbht.nhs.uk).

J Thorac Cardiovasc Surg 2021; $\mathbf{\square}: 1-2$

$0022-5223 / \$ 36.00$

Copyright (c) 2021 by The American Association for Thoracic Surgery

https://doi.org/10.1016/j.jtcvs.2021.09.051
}

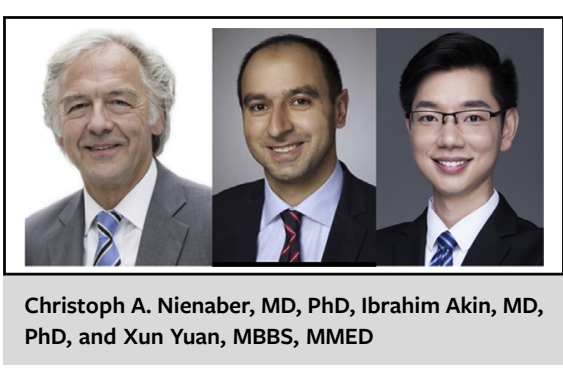

CENTRAL MESSAGE

Early minor ( $\leq 5 \mathrm{~mm}$ ) expansion of dissected aorta is a new piece in the puzzle to identify patients with type $\mathrm{B}$ dissection at high risk.

scaffolding in type B dissection ${ }^{2-4}$ both in symptomatic and asymptomatic patients. With the documented subtle enlargement of the dissected aorta usually caused by expanding diameter of the false lumen at the expense of increasingly compromised true lumen, the key has been found to better manage so-called uncomplicated type B dissection by endovascular means. Moreover, asymptomatic expansion of total aortic diameter challenges the term "uncomplicated" type B aortic dissection, as any early silent expansion within 2 weeks of impact identifies a significantly increased risk for adverse aortic events. In fact, it shatters the concept of "uncomplicated" aortic dissection and is another nail in the coffin of this misnomer. The manuscript underlines that dissection of the aorta regardless of location is a life-threatening condition, either short term in type $\mathrm{A}$, or long term in type $\mathrm{B}$ dissection. Observational studies in the past have identified a window of opportunity of about 90 days to successfully remodel dissected aorta, which essentially means that endovascular scaffolding should be performed in the subacute phase of any type B dissection. The message may broaden the indications for endovascular treatment in addition to medical management, but skepticism still lingers around focusing on costs and the risks of retrograde dissection in less than $>2 \%$. Of note, however, the safety profile of thoracic endovascular aortic repair procedures has improved considerably over the last decade and dissection-specific stents and improved operative skills are available in dedicated aortic centers. Safety issues have been successfully addressed by improved stent-graft technology with low radial force and high 
conformability ${ }^{5}$ in addition to successful learning from early mistakes such as intervening in the acute phase rather than in the subacute phase, post-ballooning, and preservation of enough spinal blood supply by revascularisation/protection of the subclavian feeder vessels.

Most importantly, the presented data moved the use of stent-graft scaffolding in so-called "uncomplicated" type B dissection from a prophylactic application into a therapeutic indication, likely with a beneficial ${ }^{1-4}$ prognostic impact on outcome. Finally, the data highlight our journey toward precision medicine in the space of aortic dissection with an individualized approach and the recommendation for early follow-up imaging before discharge and eventually surveillance for life. ${ }^{6}$

\section{References}

1. Miyoshi Y, Kaji S, Masumoto A, Kim K, Kitai T, Kinoshita M, et al. Aortic enlargement in two weeks is associated with subsequent aortic events in patients with type B acute aortic syndrome. J Thorac Cardiovasc Surg. September 18, 2021 [Epub ahead of print].

2. Akin I, Kische S, Ince H, Nienaber CA. Indication, timing, and results of endovascular treatment of type B aortic dissection. Eur J Vasc Endovasc Surg. 2009;37:289-96.

3. Nienaber CA, Kische S, Rousseau H, Eggebrecht H, Rehders TC, Kundt G, et al. Endovascular repair of type B aortic dissection: long-term results of the randomized investigation of stent grafts in aortic dissection trial INSTEAD-XL. Circ Cardiovasc Interv. 2013;6:407-16.

4. Durham CA, Aranson NJ, Ergul EA, Wang LJ, Patel VI, Cambria RP, et al. Aneurysmal degeneration of the thoracoabdominal aorta after medical management of type B aortic dissections. J Vasc Surg. 2015;62:900-6.

5. Nienaber CA, Yuan X, Aboukoura M, Blanke P, Jakob R, Janosi RA, et al. Improved remodeling with TEVAR and distal bare-metal stent in acute complicated type B dissection. Ann Thorac Surg. 2020;110:1572-9.

6. Nienaber CA. The art of stratifying patients with type B aortic dissection. J Am Coll Cardiol. 2016;67:2843-5. 